\title{
El sueño de los héroes: las máscaras del marino en Magi: Sinbad no Bōken
}

\section{Diego Hernán Rosain}

Diego Hernán Rosain nació el 24 de agosto de 1991, es licenciado en Letras por la Universidad de Buenos Aires y profesor en escuelas secundarias. Ha publicado artículos en revistas como Puesta en escena, BADEBEC y Exlibris. Actualmente, es adscripto a la cátedra de Problemas de Literatura Latinoamericana a cargo de la Prof. Dra. Marcela Croce con el proyecto titulado «Ficciones especulativas: emergencia y contacto entre las poéticas de Macedonio Fernández y Jorge Luis Borges», dirigido por el Prof. Lic. Mariano Veliz.

Fecha de recepción: 14 de agosto de 2017

Fecha de aceptación definitiva: 12 de octubre de 2017 


\title{
Resumen
}

En su momento, Simbad representó un fomento del desarrollo mercantil impulsado por la Ruta de la Seda; el Simbad de Magi: Sinbad no Bōken (2013) de Ōtaka y Ōtera también es la encarnación del self-made-man, el cual construye un emporio y acapara toda una empresa nunca antes explotada. En la actualidad, Japón es la utopía soñada por Simbad: un epicentro de la civilización moderna y productora de mercancías que llegan a todas partes del globo. En el siguiente trabajo analizaremos ciertas contradicciones presentes en el manga que reflejan un problema que Japón no ha sabido superar aún.

Palabras clave: Simbad, manga, literatura, monopolio, orientalismo.

\begin{abstract}
At the time, Simbad represented a promotion of the mercantile development impelled by the Route of the Silk; Simbad in Sinbad no Bōken (2013) by Ōtaka and Ōtera is also the incarnation of the self-made-man, which builds an emporium and monopolizes a business that has never been exploited before. Today, Japan is the utopia dreamed by Simbad: an epicenter of modern civilization and the producer of goods that reach all parts of the globe. In the following work we will analyze certain contradictions present in the manga that reflect a problem that Japan has not yet overcome.
\end{abstract}

Keywords: Simbad, manga, literature, monopoly, orientalism.

\section{Cita bibliográfica}

Rosain, D. H. «El sueño de los héroes: las máscaras del marino en Magi: Sinbad no Bōken», en CuCo, Cuadernos de cómic n.o 9 (2017), pp. 37-52. 


\section{Introducción}

En su ya clásico libro Orientalismo, publicado en 1978, Edward Said dice que «hablar de una especialidad científica que se restringe a un "campo" geográfico es, en el caso del orientalismo, bastante revelador ya que, probablemente, nadie pueda imaginar un campo simétrico llamado occidentalismo». ${ }^{1}$ Said escribía esto en un momento en que los estudios sobre el imaginario que Occidente había construido sobre el arte y la cultura oriental comenzaban a emerger y a consolidarse. Hoy en día, en una era globalizada y tras el profundo intercambio cultural entre naciones de Oriente y Occidente, sería un reduccionismo y una falacia pensar que los orientales no tuvieran una imagen, una representación, sobre la cultura occidental, que ya existía desde hace siglos y se ha vuelto aún más visible en las últimas décadas. A cada momento, los países consumen productos importados de regiones lejanas del globo que condicionan la mirada que estos poseen sobre sus lejanos vecinos. Pensar que solo Occidente tiene el privilegio de construir y formular una visión más o menos acabada de Oriente es creer que existe una relación unilateral y activa para solo una de las partes involucradas. A mi entender, uno de los más grandes fenómenos mundiales que garantiza una relación bilateral entre el hemisferio occidental y oriental es la industria cultural japonesa.

Bien conocido es el atractivo, el cual se ha transformado ya en un topoi o lugar común, que ciertos autores orientales tienen por Occidente. En la industria del manga y el anime, esto se vuelve mucho más visible: Occidente se convierte en una fuente de inspiración para miles de escritores sedientos de exotismo y novedad y cuyo apetito solo puede satisfacerse por medio de la variedad cultural. Tomemos por caso Saint Seiya de Masami Kurumada, que retoma los mitos griegos y la astrología, o Shin Seiki Evangelion de Hideaki Anno, que hace uso del sistema de creencias y símbolos judeocristiano. Más comunes son los préstamos de obras específicas: por ejemplo, hay varias adaptaciones al manga y al anime de Sherlock Holmes, el famoso personaje de Conan Doyle, así como alusiones y parodias a su obra. También es habitual ver en animes escolares representaciones de las tragedias de Shakespeare, sobre todo Romeo y Julieta, lo cual siempre funciona como pretexto para estrechar los vínculos amorosos entre protagonistas. Por último, también podemos rastrear cierta imagen de lo occidental en mangas como Hagane no Renkinjutsushi de Hiromu Arakawa o Shingeki no Kyojin de Hajime Isayama, en los cuales ciertos rasgos biológicos, geográficos y costumbristas apuntan a un contexto europeo.

Este atractivo por los textos, hábitos y espacios occidentales es inmenso y adquiere diversas formas que responden, en parte, a una fuerte influencia cuyos fundamentos se hallan en la historia y la economía que tuvieron en conjunto Japón y países como España, Inglaterra y Estados Unidos, entre otros; ${ }^{2}$ pero también es frecuente el interés por la historia y la cultura

1 SAId, E. W. Orientalismo. España, Debolsillo, 2008, p. 81.

2 Como afirma Ángel Rama en Transculturación narrativa en América Latina, la transculturación es un proceso político-histórico en el cual una cultura ejerce determinadas formas de violencia (materiales e ideológicas) sobre otra, modificando irremediablemente su percepción del mundo y su estilo de vida. Los puntos cruciales en los que ocurre este fenómeno dentro de la cultura japonesa probablemente sean la llegada del 
misma de Oriente, fuera de los límites de Japón, que, muchas veces, está atravesada por una mirada occidental. Por ejemplo, el Romance de los Tres Reinos de Luo Guanzhong y Viaje al Oeste de $\mathrm{Wu}$ Cheng'en son dos de las obras chinas con mayor adaptación al manga y al anime, entre cuyos títulos más reconocidos están Ikkitousen de Yuji Shiozaki, por un lado, y Dragon Ball de Akira Toriyama, por el otro. Con el correr de los años, la industria del manga y el anime se ha convertido en una verdadera máquina que fomenta lo que Goethe ha dado como nombre Weltliteratur (Literatura Mundial o Literatura Universal), un espacio que reactualiza constantemente los mitos más importantes que ha creado el hombre y que destaca no solo lo común y humano, sino también la mutua fecundación de lo diverso en el mundo. ${ }^{3}$ Como afirma Waltraud Kirste Teuber en su tesis, «Weltliteratun» de Goethe, un concepto intercultural, la literatura mundial no abarca únicamente al arte verbal, sino a cualquier tipo de discurso que atraviesa y rompe los límites de lo nacional y apela a la intuición y a la creatividad que hay en todo individuo. El manga y el anime, consumido por niños y adultos de todas las edades y gustos es una vía hacia el sueño goethiano de configurar discursos libres de prejuicios, llenos de aprendizajes mutuos, que acepten lo particular y cultiven lo general.

El caso que nos compete hoy es el de un clásico de la literatura universal, a saber, Las mil y una noches, el libro de relatos árabes de autor anónimo. Según María Elvira Sagarzazu, esta obra ha sobrevivido al paso del tiempo y ha logrado expandirse por todo el mundo gracias a dos elementos clave: sus personajes arquetípicos, que permiten ser ubicados en cualquier región, y su imaginario pluriterritorial, lo cual le permite ser un vehículo intercultural. ${ }^{4} \mathrm{En}$ junio de 2009, la revista Shükan Shōnen Sunday comenzó a publicar el manga de aventura y fantasía titulado Magi: the Labyrinth of Magic! (マギ: the Labyrinth of Magic!) del autor Shinobu Ōtaka, el cual retoma muchos de los personajes y temas trabajados en la tradición árabe a lo largo de los siglos. La historia se centra en Aladdin, un niño de pasado misterioso con los poderes de un magi. Cada época solo puede contar con tres magis, magos capaces de reunir el rukh de los seres vivos para su propio uso, encargados de hallar a aquellos que regirán el mundo; pero Aladdin es una anomalía por ser el cuarto magi, lo cual provoca que busque su destino a lo largo de todo el globo. Junto a él viajan Alibaba Saluja, el tercer príncipe del Reino de Balbadd, de origen bastardo, quien busca convertirse en un gobernante justo y poderoso dedicado enteramente a su pueblo, y Morgiana, una esclava que consiguió la libertad y cuya nación se halla actualmente sometida al tráfico de personas. El impacto de la historia y la identificación con los personajes fue tal que, en abril de 2013, el autor, junto con Yoshifumi Ōtera como ilustrador, crearon un spin-off de igual repercusión, que funciona

misionero navarro Francisco de Javier [el cual introdujo la lectura de las escrituras bíblicas en el territorio] (1549), el contacto con el comercio holandés (1641-1853), los cambios sociales ocurridos durante la Era Meiji (1868-1912) y su participación dentro de la Segunda Guerra Mundial [y los años de posguerra] (1939-1945), a partir de los cuales Japón sufriría profundas e irreversibles reestructuraciones políticas, económicas y demográficas, entre otras.

3 Auerbach, E. «Filología de la literatura universal», en Teorías literarias del siglo XX. Una antología. Madrid, Akal, 2005, p. 809.

4 Sagarzazu, M. E. «Introducción», en Las mil y una noches. Buenos Aires, Colihue, 2009, pp. IX-CXXIV. 
como precuela de la serie original, con uno de los personajes mejor logrados y más queridos por el público como protagonista. El manga Magi: Sinbad no Bōken (シンドバッドの冒険), en el cual nos concentraremos, narra la historia de $\operatorname{Sinbad}^{5}$ desde su nacimiento hasta los acontecimientos que lo llevaron a ser el jerarca del Reino de Sindria.

\section{El niño que quería navegar}

En la tradición arábiga, Simbad es el hijo de un comerciante adinerado de Bagdad, gracias al cual no tiene por qué preocuparse, ni trabajar para llevar una vida tranquila y rodeada de lujos. Al morir su padre, Simbad despilfarra todo su dinero y no es hasta que le quedan las últimas monedas que se da cuenta de su gran error. Decide entonces continuar con la empresa de su padre y parte a otras tierras para vender y conseguir los artículos más variados. ${ }^{6}$ La historia del origen de Sinbad aparece reformulada en Magi. Sinbad es hijo de Badr, un soldado del Imperio Parthevia, quien ha luchado honorablemente por su nación y en la actualidad se encuentra retirado, llevando una vida pacífica como pescador. Los móviles que condujeron a la guerra no quedan muy claros en la historia, pero están relacionados con el impulso expansionista y la acumulación de riquezas. Mientras el imperio logró conquistar a los países limítrofes, los ciudadanos de Parthevia recibieron beneficios por sus servicios prestados en batalla; pero cuando decidió enfrentarse directamente contra el Imperio Reim, una de las más grandes potencias a nivel mundial, la diferencia de recursos se volvió visible y los civiles dejaron de contar con la ayuda del imperio. Así, los ciudadanos se convirtieron en hombres cegados por la codicia que trae consigo la empresa bélica, y Badr, al haber perdido una pierna en batalla y cambiar su punto de vista acerca de la guerra, se convirtió en un inútil y un veterano traidor a la vista de los demás, ganándose así el título de «ex patriota».

La sed de aventura de Sinbad no será heredada de su padre, sino de Darius, un espía del Imperio Reim que se encuentra en peligro de muerte. Sinbad lo recoge malherido fuera de su casa y sus padres le prestan auxilio. Darius se presenta como un comerciante viajero caído en desgracia y, mientras se recupera, le narra al pequeño Sinbad historias fabulosas de lugares exóticos, despertando así su imaginación y curiosidad. Durante su infancia, Sinbad ya muestra signos de ser un prodigio innato. $\mathrm{Al}$ momento de su nacimiento, una serie de

5 De aquí en adelante, cada vez que aparezca el nombre «Simbad» haremos referencia al personaje tradicional de Las mil y una noches; en cambio, cuando aparezca el nombre «Sinbad» haremos referencia al personaje del manga de Ōtaka y Ōtera, siguiendo la grafía del manga.

${ }^{6}$ «El libro muestra las ventajas de ser poderoso y rico. Alá gobierna en el cielo, pero en la tierra es necesario contar con la protección que el poder asegura a quienes lo detentan y cuya contracara es el ser nadie. El poder distribuye privilegios mientras la pobreza obliga a ganarse la vida con trabajos desagradables. Y se reitera un pensamiento devenido en refrán entre los árabes: "antes muerto que pobre”. Por eso, aquí el comerciante, el marino, el mercader que viaja por tierra y por mar, encarnan modelos sociales exitosos, que gozan de los privilegios y del reconocimiento que les hubiera correspondido en cualquier otra sociedad burguesa. Se aplaude a los hombres que hacen fortuna llevando una vida de riesgos, aventuras y desafíos, porque esas lides les van a permitir vivir después sin preocupaciones. Simbad el Marino lo propone seriamente». SAGARzAZU, M. E. «Introducción», Op. cit., p. XIX. 
catástrofes naturales comenzaron a azotar a su pueblo, entre ellas un volcán inactivo que entró en erupción y una tormenta eléctrica que hizo elevar la marea. Sinbad les indicó a sus padres el camino seguro con su dedo y logró ponerlos fuera de peligro; tres años más tarde, haría lo mismo con su padre durante un viaje de pesca en el cual quedaron atrapados en medio de una tormenta. Sinbad es descripto por Badr desde entonces como aquel que tiene el poder de elegir el camino correcto, quien ha sido escogido por un gran Ser. ${ }^{7}$ Así como Simbad es protegido en sus múltiples aventuras por Alá, ${ }^{8}$ Sinbad posee un don que lo diferencia del resto de los hombres. ${ }^{9}$ El rukh se acumula a su alrededor y, sin ser un magi, lo atrae constantemente, así como Simbad es un hombre marcado por el destino. ${ }^{10}$

Sinbad perderá a ambas figuras paternas antes de comenzar su viaje: Darius muere a manos de Badr al intentar escapar utilizando al pequeño como rehén; Badr muere en el campo de batalla, obligado por el imperio a combatir ante la amenaza del exilio de su familia y de su muerte como un traidor. Luego de estos acontecimientos, ocurre un hecho que cambia el rumbo de la guerra: la aparición del calabozo (迷宮 [ダンジョン], [mēkyū (dungeon)], también llamado celda o laberinto). Los calabozos son estructuras enormes que surgen repentinamente en distintas partes del mundo. Todos los magis poseen la habilidad de erigir calabozos para escoger y dar poder a sus candidatos a reyes. Yunan es el primer magi en levantar uno y ve en Sinbad el potencial de un verdadero soberano tras prometerle a Esra, su madre, que lo guiará y lo aconsejará bien. Mientras que el ejército busca la manera de hacerse con el calabozo, Sinbad, a los catorce años, se gana la vida ofreciendo sus servicios a los forasteros, ayudando a sus vecinos o haciendo trabajos en el puerto para comprar medicinas para su madre enferma. Pero el imperio llega para solicitarle que se enliste en el ejército y forme parte de un grupo que volverá a entrar en el calabozo. Más de diez mil hombres de ambos reinos murieron intentando tomar el poder que residía allí, pero solo Sinbad logró superar todos sus obstáculos y pruebas hasta obtener el poder del djinn Baal, cuya habilidad le permite controlar el rayo con la espada de su difunto padre. Yunan le revela a Sinbad que el poder de los djinns le permitirá cambiar el rumbo del mundo y Sinbad decide emplearlo para acabar con las guerras y lograr la unión de todos los pueblos. ${ }^{11}$

El Simbad de la historia original se construye en torno a dos figuras: la del aventurero y la del comerciante. Ambas están unidas por un motivo en común: el viaje. El primer viaje de Simbad está marcado por la necesidad económica; es lo único que lo motiva a emprender el viaje que no se pretende ni se considera peligroso. Pero, tras sufrir una serie de aventuras y lograr regresar a su hogar sano y salvo con riquezas mayores a las que poseía a la hora de

7 ŌTaka, S. y ŌTera, Y. Magi: Sinbad no Bōken. Tokyo, Shogakukan, 2013, cap. 1, pp. 27-29.

${ }^{8}$ «Alá te ha dado una nueva vida: nadie logra llegar a este lugar y salir con vida, ¡da las gracias a Alá que te ha salvado!». Anónimo. Las mil y una noches, en Sagarzazu, M. E. Op. cit., p. 524.

9 Ōtaka, S. y ŌTera, Y. Op. cit., cap. 60, pp. 7-8.

10 «Todo fue obra del destino, porque de lo que está escrito, nadie se salva ni escapa». Anónimo. Op. cit., p. 509.

11 Ōtaka, S. y Ōtera, Y. Op. cit., cap. 7, pp. 1-4. 
partir, el comercio se transforma en una excusa para la aventura. ${ }^{12}$ La actitud codiciosa y temeraria de Simbad al comienzo de cada viaje se ve purgada por las penurias y las desgracias ocurridas en su transcurso, y culmina con la gracia y la generosidad que despide al entregar regalos a sus amigos, familiares y vecinos. Así se repite hasta el séptimo viaje en que Simbad se vuelve viejo y sabio y acaba por aprender la lección. ${ }^{13}$ Sinbad, en cambio, no emprende múltiples viajes, sino uno solo, largo e itinerante, a través de distintos paisajes y regiones sin retornar jamás a su hogar. Si el objetivo de Simbad es recuperar la fortuna malgastada para poder vivir bien y aventurarse para ganar experiencias vedadas a los demás hombres, Sinbad, en cambio, busca trazar una ruta comercial y crear un monopolio para así fundar su propio reino. Sinbad no es codicioso, a pesar de lo que podría aparentar, ni está sediento de aventuras; ambos son medios para alcanzar su verdadera meta, que es construir un espacio de unión y afluencia para los distintos pueblos y naciones del mundo.

$\mathrm{El}$ viaje que emprende Sinbad es físico, pero a la vez espiritual. Supone un crecimiento que no se limita a lo mercantil, sino también a lo político. La aventura queda así replegada a un segundo plano como consecuencia, o accidente, de adentrarse en lo desconocido, aunque no por eso deja de despertar gran interés. ${ }^{14}$

Sinbad posee un mayor desarrollo y profundidad psicológica que su contrapartida árabe. ${ }^{15}$ Por empezar, es un insurrecto que cuestiona directamente el poder y no teme enfrentarlo; pero, a su vez, desea ostentarlo con fines benévolos. Es un plebeyo que inspira esperanzas en el pueblo y odio en la realeza. Es un marginal y un outsider, porque busca crear una nue-

12 «[...] decidí quedar residiendo en Bagdad por un tiempo, disfrutando de la vida en el colmo de la prosperidad y alegría, hasta que me invadió de pronto la añoranza del viaje y la aventura, y volví a sentir ansias de comerciar y lucrar, como que el hombre está inclinado al mal». ANónimo, op. cit., p. 527.

13 «Los viajes de Simbad aluden a la ancestral ambición de extender el potencial humano en cualquier dirección posible. La propuesta misma parece una respuesta de los mortales limitados por el tiempo de vivir, frente a cuya brevedad, el espacio se abre como una compensación. Los viajes ayudan a descubrir ese costado de la existencia que admite ampliaciones. Si Alá ha decretado desde el principio la duración de cada vida, no hay límites a propósito de hasta dónde y en qué puede emplearla cada uno [...]. Todo ese material yace distribuido por la geografía del planeta y a disposición de los mortales. Lo terrenal, pues, constituye un arca, un cofre, un paraíso abierto al aventurero rico o pobre. La narración oficia de vehículo hacia esas promisorias regiones. Hay, pues, no solo una Tierra Prometida, sino muchas, hay bienes de todo tipo a cambio de agallas y sufrimientos, pero la vida es una generosa opción, igualadora en cuanto a las limitaciones». SAgarZaZu, M. E. Op. cit., p. XII.

14 ŌTaka, S. y ŌTera, Y. Op. cit., cap. 7, p. 5.

15 «Simbad [...] nos convence de su existencia sin revelarnos los movimientos de su psique ni su personalidad. No hay reflejos ideológicos, sus pensamientos se adecuan a lo que el destino ya ha dispuesto y su intervención se limita a obrar para sobrevivir. [...] lo interesante es que su conducta revela mejor que nada cómo es. Pero, como precisamente el fatalismo excusa al individuo de tomar las riendas de su existencia, los protagonistas de Las mil y una noches no son un canto al esfuerzo personal, ni a la arabidad, ni a la religión, ni a las costumbres, y esos seres desprovistos de motivos para forjarse una personalidad individual dejan abierta la puerta al modelo universal o universalizable. Su originalidad los ha consagrado como iniciadores de una estirpe literaria, y los avatares del libro mismo, el largo proceso de acopio y decantación de elementos, hicieron que las generaciones posteriores reconocieran en esos perfiles algo auténticamente árabe». Sagarzazu, M. E. Op. cit., p. XXVIII. 


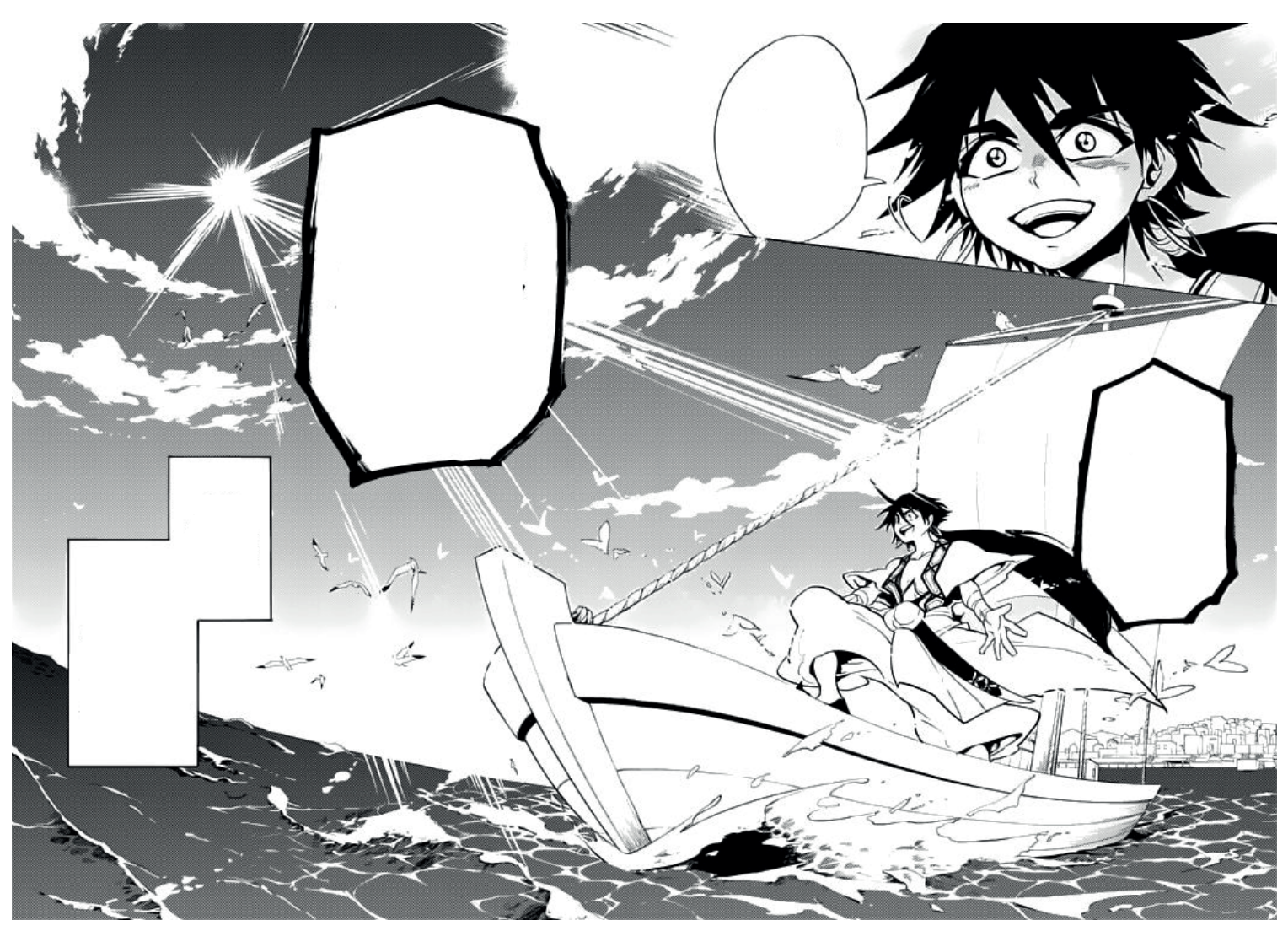

FIG. 1. ŌTaka, S. y ŌTera, Y. Op. cit., cap. 12, pp. 28-29.

va legalidad fuera de los límites del Imperio Parthevia. En su aventura, se va topando con distintos jerarcas a los cuales cuestionará o con cuya manera de gobernar coincidirá. En su sexto viaje, Simbad entra en contacto con el rey de Hind, a quien admira y respeta. Tanto este último como el califa Harún ar-Rashid son correctos modelos de gobernantes a seguir. Por lo tanto, lo político ocupa un rol predominante en ambas obras. Ahora bien, ¿qué es lo que hace a un buen monarca? Por un lado, el amor por su pueblo. Como vimos, la juventud de Sinbad está marcada por el despotismo y la tiranía de los imperios. La guerra le obliga a sufrir las más grandes atrocidades, tanto a él como a sus semejantes. Cuando Sinbad se encuentra con los príncipes de Parthevia, se encarga de dejarles bien en claro que un país subsiste gracias a su pueblo y no por sus gobernantes. En segunda instancia, un buen rey debe ser un buen estratega no solo en la guerra, sino también en los negocios. Es así como aprende de Rashid Saluja, rey de Balbadd y padre de Alibaba, estrategias comerciales y de negocio que le serán de gran utilidad a lo largo de su viaje. Además, Sinbad posee un gran corazón y se gana fácilmente la confianza de las personas por dos motivos: su habilidad retórica y su capacidad para contar historias.

Sinbad es un gran orador. Su arma más certera no es su espada, su buena suerte o sus djinns, sino su destreza verbal; su don es la palabra. Sinbad convence con sus discursos hasta al más sanguinario de sus enemigos porque son claros y auténticos. En contraposición a los jefes y 
superiores que enervan a las masas con alegatos vacíos y opacos, que ocultan fines mezquinos enarbolando banderas como las del imperio o la religión, las prédicas de Sinbad resultan puras y sinceras. Es el líder carismático que despierta amor en las mujeres, respeto en los hombres y admiración en los niños. Por otro lado, también es un gran narrador. Sinbad, como en Las mil y una noches, convence relatando sus maravillosas historias; su autobiografía lo salva en los momentos de mayores penurias. Como relator, también comercia con su vida, ganando todo tipo de favores de extraños y extranjeros. Por un tiempo, cuando el único recurso que le queda es su propio cuerpo, llega a oficiar de artista callejero y, como un juglar, cuenta sus andanzas frente a un enorme público a cambio de monedas. ${ }^{16}$ Por fin, termina publicando una pequeña autobiografía que cuenta cómo logró capturar a sus dos primeros djinns para recaudar fondos y así continuar con su viaje. Su fama, la cual todos oyeron pero nadie conoce, lo saca a flote cuando se está hundiendo. ${ }^{17}$ La competencia lingüística, como vimos, es de suma importancia para ambos personajes.

Por último, cabe destacar su rol como diplomático. Simbad asume a lo largo de sus siete viajes diversos roles como funcionario que le conceden una jerarquía mayor que la del resto de los hombres; en dichos oficios aprende a relacionarse con los demás, ya sean subordinados o superiores suyos. Las relaciones públicas son muy importantes durante sus estadías en los distintos lugares en los que habita, y es por eso que aprende a desarrollarlas. Sinbad, a su vez, opera como embajador de un país que todavía no existe: Sindria. Antes de fundar dicho reino, comienza a trazar y firmar pactos con los gobernantes más intimidantes y obstinados que se puedan imaginar, para así generar un clima de confianza y apertura tanto política como económica. Además de ser un emisario de la paz, Sinbad es la encarnación y el paroxismo del self-made-man. ${ }^{18}$ Todo lo que sabe lo aprende por su cuenta; no es su fuerza ni su suerte lo que lo distinguen del resto, sino su ingenio. ${ }^{19}$ En su camino, irán apa-

${ }_{16}$ Este tipo de autoexplotación no es criticada en el manga, pero, cuando Sinbad apuesta su propia libertad y confía ciegamente en su buena suerte para salvar su compañía sin pensar en las consecuencias, pareciera que el propio rukh, que hasta entonces lo protegía de todo mal, acaba por abandonarlo. Al convertirse en esclavo, conoce el lado oscuro del comercio: el tráfico de personas. A partir de allí, emprenderá una catábasis y deberá sufrir torturas jamás transitadas hasta entonces para recuperar su lugar en el mundo.

17 «[... el prestigio se busca afanosamente, destacarse como algo especial del resto del rebaño [...]. La fama es obtener todos los beneficios del trabajo colectivo en el reposo. La imagen que el famoso irradia le asegura su sustento; se vende a sí mismo para siempre. Es como haber arribado al oro de la personalidad convirtiendo la hazaña misma en medio de subsistencia, venta del propio ser superado.

»Pero para que esto ocurra es imprescindible constituirse en noticia, ser propalado por los medios masivos de comunicación y reconocido por la "opinión pública”. Al personaje no puede bastarle la aventura misma como recompensa: si es solitaria no tiene sentido, porque él actúa para la galería, y su acción tiene significado en cuanto los demás sepan que él los ha superado [...]. Por eso, no importa la verdad, sino la apariencia. El buen nombre del protagonista depende exclusivamente de la historia como chisme». Dorfman, A. y MatTelart, A. Para leer al Pato Donald: Comunicación de masas y colonialismo. Buenos Aires, Siglo Veintiuno Editores, 2014, pp. 144-145.

18 «He aquí el mito básico de la movilidad social en el sistema capitalista. El self-made-man.Igualdad de oportunidades, democracia absoluta, cada niño parte de cero y acumula lo que se merece [...]. Todos nacen con la misma posibilidad de ascenso vertical, por medio de la competencia y del trabajo (sufrimiento y aventura, y la única parte activa, la genialidad)». Ibid., p. 135, las cursivas son suyas.

19 Los casos más claros en los que Sinbad sale ganando gracias al uso de su ingenio son, por un lado, la captura del djinn Valefor, por el cual competía contra otros cinco candidatos más y gana sin necesidad de utilizar 
reciendo maestros, como Rurumu, hija del jefe de Imuchakk y diplomática de su tribu, que le enseñará a leer, escribir y navegar, entre muchas otras cosas, o Rashid, que le enseñará gajes sobre el oficio del mercader y el buen comerciante; pero el mejor maestro de Sinbad es él mismo. La experiencia que va acumulando a lo largo de sus viajes traza el camino que lo conduce a ocupar el trono de Sindria, un lugar que busca funcionar como la federación del mundo entero, a través de la cual el poder converge y fluye a todas las regiones. Cada país, pueblo o imperio podrá mantener así su autonomía, pero reconocerá al resto como tal. Para eso, un reino regulador como Sindria es necesario. Sinbad abraza las diferencias y cree en la tolerancia y el diálogo como medio para alcanzar la paz; pero, a su vez, esa paz solo puede ser lograda por medio de la creación de un ente que se encargue de velar por ella.

\section{La verdad detrás del discurso}

El discurso de Sinbad no es ingenuo. A pesar de su corta edad y del manto de inocencia que lo cubre, reconoce que el mundo se mueve en torno al dinero; es por eso que, delante de su meta, corre un afán mercantilista. La superestructura, su pensamiento, está supeditada a la base material, sin la cual el deseo de crear un mundo sin guerras sería tan solo un sueño vacío. Sinbad propone un modelo global alrededor de la ciudad mercante que se contrapone a otros sistemas de la antigüedad, como podrían ser el de la ganadería o el de la agricultura. Ese modelo es el que predomina hoy en día y el que Japón ocupa dentro de la gran aldea global, un rol central y ejemplar como productor y exportador de mercancías materiales y simbólicas. ${ }^{20}$ Japón, que en sus inicios recibió una gran influencia cultural por parte de China, que más tarde fue presionado por los grandes Estados industrializados de Occidente para abrir y expandir sus relaciones comerciales durante la Era Meiji, y que, luego de su derrota durante la Segunda Guerra Mundial, fue ocupado y su estructura política reorganizada por extranjeros, logró reponerse y llevar a cabo un lento y paulatino proceso de modernización, reconstrucción y estabilidad social que le permitieron posicionarse, en la actualidad y tras una serie de altibajos, como una de las más grandes potencias económicas a nivel mundial. ${ }^{21}$ Como sostiene W. J. Macpherson en su libro The economic development of Japan, c. 1868-1941, según la lectura que hace de él Zalduendo,

la fuerza (pero engañando a sus oponentes); y, por el otro, el escape del Valle de los Muertos, episodio que retoma la misma táctica de escape que Simbad utiliza en su segundo viaje, aferrándose a la carne que recoge el ruj.

20 «En efecto, Japón es hoy la segunda economía del mundo, si tenemos en cuenta el tamaño de su producto nacional bruto; también, la tercera, si consideramos su producto por habitante (en este caso, detrás de Suiza y Luxemburgo); es el tercer país según el Índice de desarrollo humano de las Naciones Unidas, detrás de Canadá y Suiza; el primero, según la expectativa de vida al nacer (80 años); muestra la menor tasa de desempleo (2,9\% de la población económicamente activa), y, además, registra la menor tasa de mortalidad infantil (4 \%)». Zalduendo, A. E. «El desarrollo económico de Japón», en Boletin de Lecturas Sociales y Económicas de la Universidad Católica Argentina, año 2, n. 7 (1995), p. 17.

${ }^{21}$ Entre las características y comportamientos que favorecieron el rápido crecimiento de Japón con respecto a otros países, en el plano económico suelen destacarse: la mayor importancia del grupo frente al individuo; la disciplina que se expresa en la aceptación de la autoridad y la lealtad a la familia y a los superiores; la utilización de los excedentes de mano de obra; el apoyo constante de ciertas instituciones estatales; el 
el crecimiento japonés fue, como no podía ser de otra manera, el resultado final de la acción de muchas variables económicas y no-económicas. [Pero] el desarreglo se presentó cuando la mezcla del esfuerzo de modernización y un mayor absolutismo condujo a un tipo de capitalismo imperialista tan agresivo como el que mostraba Occidente en esa misma región a fines del siglo xIX y que le servía de modelo. ${ }^{22}$

Magi: Sinbad no Bōken, aun apuntando a un público infantil y adolescente, configura un espacio ficticio en el cual la monopolización de un mercado se ve justificada por un fin benévolo, sin abordar los problemas que esto podría llegar a acarrear en el mundo real. ${ }^{23}$ Como afirman Dorfman y Matterlart, «lo imaginario infantil es la utopia pasada y futura del adulto. Pero, precisamente por constituirse en el reino interior de la fantasía, es ahí, en ese modelo de su Origen y de su Sociedad Futura Ideal, donde se reproducen con libertad todas las características que lo aquejan». ${ }^{24}$ Japón ha quedado atrapado entre la sociedad agrícola impermeable del pasado y la sociedad mercantil industrializada y altamente tecnológica moderna; en su manga, Ōtaka y Ōtera proponen una salida ficticia al problema en el cual un imperio (Sindria/Japón) abastece y regula otros puntos estratégicos, entablando proyectos en conjunto, controlando así su propia autonomía, existencia y pervivencia pacífica.

Sinbad es el adulto disfrazado de niño, vocero de un sistema que busca reproducirse y legitimarse con cada reactualización de su discurso. Los lazos que entabla con sus semejantes se fundan ante todo sobre relaciones comerciales: cuando zarpa por primera vez hacia la aventura, Sinbad «regala» todos los bienes adquiridos en la conquista del primer calabozo a sus vecinos y amigos para que recuperen parte de lo que les ha sido quitado por el Imperio de Parthevia; cuando debe hacerse con un barco y mercadería para emprender su negocio, utiliza el oro obtenido en la conquista del segundo calabozo. Esas riquezas no se generan ni se fabrican, simplemente aparecen, no como fruto del trabajo, sino como producto de la magia, como recompensa por el esfuerzo y la habilidad. ${ }^{25}$ Ese dinero no tiene historia, sino

comportamiento del consumidor japonés por su baja propensión marginal a consumir, su alta capacidad de ahorro y la persistencia en mantener sus pautas de consumo tradicionales; la importancia otorgada a la experimentación práctica, junto con la particular capacidad para adaptarse y para aceptar los cambios en el campo de la producción; la existencia de pequeñas y medianas empresas que actúan como empresas «madres», proporcionando financiamiento, materias primas, maquinarias, consejos para la administración, asistencia técnica, diseños y control de calidad; una visión más complementaria y menos competitiva del mercado, lo cual pone en tela de juicio la racionalidad económica del capitalismo occidental; el rol que juegan en los negocios la confianza mutua, las diversas lealtades, la estabilidad de la fuerza del trabajo y el sistema salarial que valora la antigüedad». Zalduendo, A. E. Op. cit., pp. 22-23.

22 Ibid., p. 23.

${ }^{23}$ «Esa comarca simple, llana, traslúcida, hermosa, casta, pacífica, que se ha promovido como salvación, en realidad importa, de contrabando e involuntariamente, el mundo adulto conflictual y contradictorio. El diseño de ese mundo transparente no hace sino permitir el encubrimiento y la expresión subterránea de sus tensiones reales y fatigosamente vividas». Dorfman, A. y Mattelart, A. Op. cit., p. 28.

${ }^{24}$ Ibid., p. 29, las cursivas son suyas.

25 «La mala fortuna acumula riesgos y dolores en el camino de los héroes, para que la buena fortuna pueda premiarlos al final con el oro. No es fácil llegar hasta el oro: hay que sufrir el trabajo desconcretizado, el trabajo como aventura». Ibid., pp. 120-121, las cursivas son suyas. 
hasta que alguien logra conquistarlo. ${ }^{26}$ Sin embargo, no se posee por demasiado tiempo y se mantiene en constante circulación y transformación. Diferente es el caso del dinero que Sinbad obtiene por medio del comercio, el cual no administra ni maneja en última instancia, salvo en contadas ocasiones, lo cual ocasiona que, en un punto de la historia, por culpa de uno de sus empleados de confianza, la compañía genere una gran deuda con otro competidor. Ese dinero, con el cual se comercia, se contrapone claramente al oro obtenido durante la aventura del calabozo, que no se sustrae por ningún proceso productivo. Tampoco vemos las condiciones de producción de las mercancías, solo su adquisición y posterior venta. El manga se saltea los momentos de extracción, trabajo y elaboración de las mercancías para concentrarse únicamente en su venta y distribución, negando así la existencia de una verdadera fuerza de trabajo. El dinero es esa presencia que pulula y se multiplica a su alrededor constantemente, pero de la cual es necesario desprenderse rápidamente para poder continuar, ya que estorba o interfiere con el verdadero fin. Ascetismo y acumulación conviven continuamente en Sinbad no Bōken, a la vez que niega la existencia de la mayoría de los actores que participan de aquel circuito monetario. ${ }^{27}$ Así, el mundo de Magi se mueve entre las aristas de un feudalismo tardío y un protocapitalismo en donde Sinbad navega a sus anchas.

Cuando el dinero no lleva a ningún acuerdo, Sinbad apela a un poder físico-mágico que somete hasta al más terco y despótico monarca: el líder militar y fanático religioso Darius Leoxses se somete a la voluntad de Sinbad y confía en él solo cuando cae en la cuenta de que no puede vencer a su equipo djinn; la amazona misándrica Mira Dianus Artemina se

${ }^{26}$ «El origen de esa riqueza es un dilema que nunca se plantea. El único propietario legítimo del objeto es el que se le ocurre buscarlo: lo crea a partir de su brillante idea de salir a su encuentro. Antes, en realidad, no existía en ninguna parte. La civilización antigua es el tío del objeto, y el padre es el que se queda con él al haberlo descubierto, al haberle rasgado la cobertura del tiempo [...]. La dificultad nunca está en la extracción de la materia, es ajena a la materialidad del objeto: es blando y no opone resistencia al cuerpo. Solo juega a las escondidas, y, por tanto, lo que se necesita es astucia para extraerlo de su refugio y no fuerza de trabajo para labrar su contenido, para darle una forma, es decir, sacarlo de su naturaleza meramente física y mineral y hacerlo ingresar al mundo humano. Se incorpora la riqueza a la sociedad mediante el espíritu, mediante las ideas y las ampolletas que se iluminan». Ibid., pp. 96-98. Podría objetarse que el tesoro le corresponde al Estado, imperio o nación dentro del cual el calabozo aparece, pero algunos límites territoriales parecen no ser del todo claros y, aun así, no cualquiera posee la habilidad para sortear todas las dificultades que la aventura implica. Lo cierto es que el tesoro, así como el djinn que reina allí, es propiedad única y exclusiva de aquel que logre conquistarlo.

27 «La avaricia, entonces, que causa tanta risa no es sino la pantalla para empobrecerlo y devolverlo a su punto de origen, para que así pueda probar y clamar eternamente su valor. Además, esta tacañería es el defecto de una cualidad: la famosa cualidad del empresario burgués que Weber y Von Martin han estudiado. Signo de su predestinación para el éxito, posibilidad moral para apropiarse sin gastar, y de la inversión en el comercio y la industria olvidándose de la propia persona. Para el burgués, esta ascesis era el signo de su predestinación para el éxito, era la posibilidad moral de adueñarse del trabajo ajeno sin gastar, sin macularse. Pero el propósito de eso era la re-inversión en el comercio y la industria [...]. La otra cualidad que asegura su supremacía es que siempre lleva la iniciativa. Es una máquina de ideas y cada una genera riqueza sin mediadores. Es la culminación de la división entre trabajo intelectual y trabajo manual. Sufre como obrero y crea como el capitalista». Ibid., p. 136, las cursivas son suyas. El momento de mayor ascetismo de Sinbad se visualiza en el Valle de los Muertos, cuando debe llevar un estilo de vida austero y primitivo que lo retrotrae a su niñez sencilla, pero feliz. Todo su viaje irá olvidando y recordando esta forma de vida, tanto en los momentos de extrema pobreza como en los de mayor riqueza. 


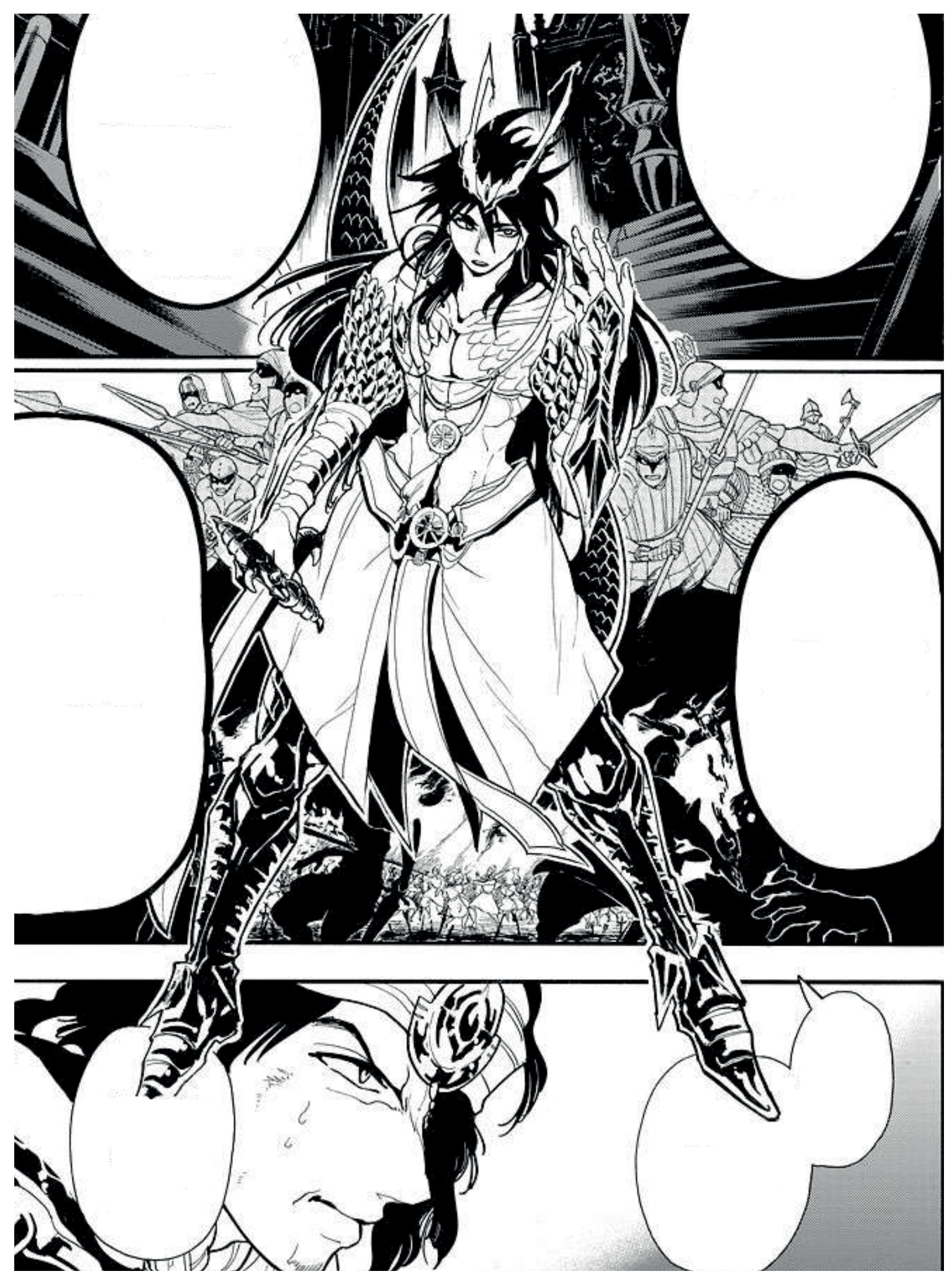

FIG. 2. ŌTAKa, S. y ŌTera, Y. Op. cit., cap. 44,

p. 5 . 
convierte en su aliada para que, en un futuro, Sinbad no se convierta en una amenaza para ella y su pueblo. Sin herir de gravedad o muerte a ninguno de sus aliados, Sinbad emplea la violencia como herramienta para convencer cuando se han agotado el resto de los recursos. La otra cara del pacifista linda con la del conquistador y hasta con la del terrorista, el cual impone su punto de vista al más débil por medio del miedo.

Aquella es una mirada que ya no mira hacia el pasado, sino hacia el futuro, a un período de superación y redención de los pecados y crímenes de guerra, de las atrocidades causadas por las desigualdades de poder y por el despotismo de los tiranos. Este imperialismo comercial inaugura una etapa de entendimiento mutuo en un presente en el cual persisten las diferencias y los conflictos entre naciones. Sinbad es un revolucionario en tanto nos focalicemos en sus ideales de cambio a nivel mundial, pero sus métodos no dejan de ser los mismos que emplean sus oponentes para sostener el orden establecido. Lo que lo distingue de los antagonistas es cierto orden ético, al cual apuntan sus pensamientos. ${ }^{28} \mathrm{La}$ bondad que representa a Sinbad es lo único que diferencia y justifica sus nobles actos de las atrocidades que comete Barbarossa, el primer teniente del Imperio de Parthevia. ${ }^{29}$ Como representante del progreso, la civilización y la paz entre las culturas, se contrapone a aquellos que amenazan con destruir todo lo que él personifica; es el dominador que puede inmiscuirse en asuntos de Estado gracias a su orientación ética y moral.

De una manera no del todo anacrónica, ${ }^{30}$ Ōtaka y Ōtera idean, a partir de las aventuras de Simbad, una defensa a la explotación del comercio concedido legalmente a un individuo, sin plantear todas las contradicciones reales y conflictos verdaderos que esto implica. Esto responde al deseo de retornar a una etapa serena y tranquila de producción, sin la necesidad de preocuparse por peligros externos que amenacen el sistema económico. Sinbad padece la obsesión de volver a un tipo de organización social que ha sido arrasado por la «civilización». Para ello, el joven adulto recorre los lugares más exóticos y ajenos a su hogar para

${ }^{28}$ Durante el cuarto viaje de Simbad, el marino se ve obligado a asesinar para poder sobrevivir, ya que fue encerrado en las profundidades de una caverna a causa de las costumbres de un pueblo, las cuales desconocía hasta ese momento y no compartía en absoluto. El asesinato se ve justificado en la medida en que la muerte es inminente, se mata para preservar la propia vida y solo se realiza en circunstancias extremas; este acto se presenta con total naturalidad y ni siquiera es cuestionado por los comensales que oyen la historia. De igual manera, el manga naturaliza las acciones de Sinbad, a pesar de que el lector pueda no estar del todo de acuerdo con su proceder.

29 «Se ha transcrito la explotación justificándola, se ha demostrado que, en ese mundo, solo ese poseedor puede seguir creando la riqueza como su dominio exclusivo y que, en definitiva, todo lo que él ha ganado en el pasado se contagia de legalidad. Si los burgueses tienen el capital y son los dueños de los medios de producción ahora, no es porque alguna vez explotaron a alguien o acumularon inválidamente: se afirma, a través del proceso contemporáneo, que el origen de la riqueza del capitalista surgió en idénticas circunstancias, que sus ideas siempre le dieron la ventaja en la carrera hacia el éxito. Y sus ideas lo sabrán defender». Dorfman, A. y Mattelart, A. Op. cit., p. 113.

30 Para la época en que la historia de «Simbad, el marino» pasó a formar parte de Las mil y una noches, el modelo de ciudad al cual aspiraba Arabia Saudita se contraponía fuertemente a otros, como el de Egipto. La Meca se consideraba un fuerte punto de afluentes que conectaba las rutas mercantiles de Oriente y Occidente, siendo Simbad el propagador y defensor de dicho modelo. 
hallar una respuesta a la nostalgia de su niñez; pero ni Imuchakk, ni Reim, ni Sasan, ni Artemyra, ni Heliohapt son su verdadero hogar. Ante esa inminencia, la única solución que encuentra es la instauración de un comercio fuerte y autoritario regido por un grupo bondadoso y caritativo que controle y regule las acciones a nivel mundial. Si no puede encontrar un nuevo hogar, no tendrá más opción que crear uno a partir de su imaginación, liquidando sin escrúpulos a quien se interponga en su camino. ${ }^{31}$

\section{Conclusión}

Hemos visto cómo es que Ōtaka y Ōtera construyen un personaje carismático y divertido que convence a todos con su sonrisa y sus buenas intenciones; sin embargo, aquel niño oculta las fantasías del adulto que teme que sus sueños y aspiraciones sean quebrantados, una vez más, por las violentas y caóticas políticas económicas internacionales. Para combatir aquel futuro posible, los autores crearon un mundo de fantasía en el cual todo marcha bien para el protagonista, aunque las fisuras del sueño de Sinbad ya comenzaron a salir a flote.

Su encuentro con Ōmu Madōra le demostró que su habilidad no lo vuelve inmune a todo peligro. Su arrogancia hizo que pasara una temporada como esclavo y fuera víctima de torturas físicas y psicológicas, haciendo que su carácter flaqueara hasta bloquear su voluntad. Al final, el saldo de niños muertos que dejó su revolución de esclavos le enseñó que sus decisiones también generan graves consecuencias en las que no todos salen indemnes, y que su postura afecta tanto a él como a quienes lo rodean. La lucha retórica que posee con la princesa Serendīne de Parthevia por la posesión del djinn Zepar también supone una derrota y un quiebre en los sueños de Sinbad: Serendīne le muestra cómo es que él se aprovecha de las situaciones que genera para imponer su imagen de un mundo vago y vacío a sus aliados, un mundo que cualquiera puede desear por su alto grado de idealización. Pero lo más importante es que Serendīne separa lo económico de lo político: ella convence a Sinbad de que, para cambiar el rumbo de las acciones e influir en las naciones con las que entabla alianzas, solo necesita del poder económico; mientras que, si escoge fundar un país, precisará priorizar la vida y el bienestar de sus ciudadanos antes que los de los habitantes del mundo, dejando la diplomacia en segundo término. Los roles de un líder y un rey son incompatibles; mientras que Sinbad juega el rol de un líder carismático, no puede ocupar el lugar de un rey porque no posee un linaje real, ni puede abandonar su papel activo por la pasividad del símbolo monárquico. Serendīne le da una solución a su problema: ella será la reina de Parthevia, tierra natal de ambos, mientras Sinbad, como su esposo, podrá llevar a cabo sus políticas externas. ${ }^{32}$

Si Sinbad cumple o no con su promesa, aún está por verse. Como rey de la isla de Sindria, como el legendario conquistador de calabozos, como portador del poder de siete djinns,

31 Ōtaka, S. y ŌTera, Y. Op. cit., caps. 80-81.

32 Ibid., caps. 102-104. 
como encargado de la empresa comercial de su país y como líder de la Alianza Internacional de los Siete Mares, todavía no ha revelado su verdadero plan ni ha cumplido su sueño. ${ }^{33}$ Las disimuladas contradicciones salen a flote lentamente; aun así, el mundo de fantasía creado por el niño debe mantenerse intacto para que la aventura pueda continuar.

\section{BibLiografíA}

Anónimo. Las mil y una noches, en Sagarzazu, M. E. (trad.). Buenos Aires, Colihue, 2009.

Auerbach, E. «Filología de la literatura universal», en Teorías literarias del siglo XX. Una antología. Madrid, Akal, 2005, pp. 809-820.

Dorfman, A. y Mattelart, A. Para leer al Pato Donald: Comunicación de masas y colonialismo. Buenos Aires, Siglo Veintiuno Editores, 2014.

Kirste Teuber, W. «Weltliteratun» de Goethe, un concepto intercultural. Alicante, Biblioteca Virtual Miguel de Cervantes, 2001. Disponible en: http://www.cervantesvirtual.com/ nd/ark:/59851/bmcpv6g4.

Ōtaka, S. y Ōtera, Y. Magi: Sinbad no Bōken. Tokyo, Shogakukan, 2013.

Rama, Á. Transculturación narrativa en América Latina. Buenos Aires, Ediciones E1 Adariego, 2008.

Sagarzazu, M. E. «Introducción», en Las mil y una noches. Buenos Aires, Colihue, 2009, pp. IX-CXXIV.

SAId, E. W. Orientalismo. España, Debolsillo, 2008.

Zalduendo, A. E. «El desarrollo económico de Japón», en Boletin de Lecturas Sociales y Económicas de la Universidad Católica Argentina, año 2, n. 7 (1995), pp. 17-28.

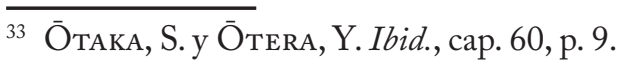

